\title{
FORMULASI SEDIAAN PASTA GIGI DENGAN ARANG AKTIF TEMPURUNG KELAPA (Cocos nucifera L) SEBAGAI PEMUTIH GIGI
}

\author{
Liana Febrianti ${ }^{1}$, Desy Nawangsari ${ }^{1 *}$, Adita Silvia F $^{1}$ \\ ${ }^{1}$ Universitas Harapan Bangsa, Purwokerto, Indonesia \\ *corresponding author \\ Email: desynawangsari@uhb.ac.id
}

Diterima : 17 September 2021

Direvisi : 12 Oktober 2021

Publikasi : 20 Oktober 2021

doi:10.52216/jfsi.vol4no2p50-57

\begin{abstract}
Teeth are one of the important aesthetic factors for a person, including tooth color. The effect of tooth discoloration can cause a person's lack of self-confidence. The use of teeth whitening agents can cause side effects in the oral cavity so that the use of natural ingredients is chosen as a tooth whitener, one of which is activated charcoal. Activated charcoal has an absorption capacity of 25-100\%. The purpose of this study was to evaluate the physical properties and activity of coconut shell-activated charcoal toothpaste a teeth whitener. The data was obtained qualitatively using the Shade Guide Vitapan Classical method and then statistically analyzed using One Way ANOVA Sig > 0.05. This study used 20 dentures and then soaked them in coffee solution for 17 days to change the color of the teeth. Teeth whitening activity test was carried out for 14 days. Toothpaste was made in 4 formulas with different concentrations of coconut shell-activated charcoal in formula 1 (0\%), formula 2 (6\%), formula 3 (10\%) and formula $4(12 \%)$. The results of the observations showed that the evaluation of physical properties had good results including organoleptic tests, homogeneity tests, $\mathrm{pH}$ tests and viscosity tests. The results of the teeth whitening activity test were able to give a change in the color of the teeth in formulas 2, 3 and 4. Statistical tests showed that coconut shell-activated charcoal toothpaste had a significant difference in activity as a natural ingredient for whitening teeth.
\end{abstract}

Keywords: activated charcoal, teeth whitening, toothpaste

\section{Intisari}

Gigi merupakan salah satu faktor estetika penting bagi seseorang, termasuk warna gigi. Pengaruh perubahan warna gigi dapat menimbulkan kurangnya rasa percaya diri seseorang. Penggunaan bahan pemutih gigi dapat menimbulkan efek samping pada rongga mulut sehingga membuat pemanfaatan bahan alam dipilih sebagai pemutih gigi salah satunya adalah arang aktif. Arang aktif memiliki daya serap sebesar 25-100\%. Tujuan penelitian ini adalah untuk mengetahui evaluasi sifat fisik dan aktivitas sediaan pasta gigi arang aktif tempurung kelapa sebagai pemutih gigi. Data diperoleh secara kualitatif dengan metode Shade Guide Vitapan Clasiccal selanjutnya dianalisis secara statistik menggunakan One Way ANOVA Sig >0,05. Penelitian ini menggunakan gigi palsu sebanyak 20 buah kemudian direndam dengan larutan kopi selama 17 hari untuk mengubah warna gigi. Uji aktivitas pemutih gigi dilakukan selama 14 hari. Pasta gigi dibuat sebanyak 4 formula dengan perbedaan konsentrasi arang aktif tempurung kelapa pada formula 1 (0\%), formula 2 (6\%), formula 3 (10\%) dan formula 4 (12\%). Hasil pengamatan menunjukkan evaluasi sifat fisik mempunyai hasil yang baik meliputi uji organoleptik, uji homogenitas, uji pH dan uji viskositas. Hasil uji aktivitas pemutih gigi mampu memberikan perubahan 
warna gigi pada formula 2, 3 dan 4. Uji statistik menunjukkan bahwa pasta gigi arang aktif tempurung kelapa memiliki perbedaan aktivitas yang signifikan sebagai bahan alami pemutih gigi.

Kata kunci: arang aktif, pasta gigi, pemutih gigi

\section{Pendahuluan}

Gigi adalah salah satu faktor estetika penting bagi seseorang, termasuk warna gigi (Yuniarti et al., 2016). Perubahan warna gigi dapat mempengaruhi kurangnya rasa percaya diri seseorang walaupun bentuk dan susunannya telah ideal (Torres et al., 2013). Perubahan pada warna gigi dapat disebabkan oleh makanan, kopi dan teh (Asmawati \& Aulia, 2016).

Perawatan pemutihan gigi secara garis besar dibagi menjadi dua metode antara lain bleaching gigi dan prosedur profilaksis rutin seperti menyikat dengan pasta gigi pemutih. Prosedur bleaching dikenal lebih mahal daripada prosedur profilaksis dengan pasta gigi pemutih sehingga banyak orang yang memilih penggunaan pasta gigi pemutih daripada bleaching (Rahardjo et al., 2015).

Menurut American Dental Association (ADA) bahan untuk memutihkan gigi yang telah disetujui yaitu carbamide peroxide $10 \%$. Penggunaan bahan pemutih gigi dapat menyebabkan timbul efek samping seperti iritasi giginya, sakit tenggorokan, reaksi alergi dan gigi sensitif (Riani et al., 2015). Efek samping yang ditimbulkan tersebut membuat pemanfaatan bahan alam dipilih sebagai pemutih gigi karena memiliki efek samping yang relatif minimum dibandingkan dengan bahan kimia sintesis (Maesaroh dan Euis, 2018).

Menurut Pertiwi et al. (2017) arang atau karbon aktif adalah salah satu bahan yang memiliki kemampuan untuk menyerap kotoran dan sangat baik dalam membersihkan celah gigi yang sulit dibersihkan. Bahan baku yang dapat dibuat menjadi karbon aktif adalah semua bahan yang mengandung karbon baik yang berasal dari tumbuh-tumbuhan, binatang ataupun barang tambang, seperti berbagai jenis kayu, sekam padi, tulang binatang, batu-bara, tempurung kelapa, kulit biji kopi. Bahan-bahan tersebut jika dibandingkan, tempurung kelapa merupakan bahan terbaik yang dapat dibuat menjadi karbon aktif karena memiliki mikropori yang banyak, kadar abu yang rendah, kelarutan dalam air yang tinggi dan reaktivitas yang tinggi (Pambayun et al., 2013). Selain itu arang aktif memiliki daya serap sangat besar, yaitu 25-100\% terhadap berat arang aktif (Saputro et al., 2020).

Saat ini pemanfaatan arang aktif sebagai komponen pasta gigi belum maksimal. Oleh karena itu, perlu dilakukan penelitian mengenai Formulasi Sediaan Pasta Gigi Dengan Arang Aktif Tempurung Kelapa (Cocos nucifera L) Sebagai Pemutih Gigi.

\section{Metode Penelitian}

\subsection{Alat dan Bahan}

Alat yang digunakan meliputi mortir dan stamper, hot plate (thermo scientific, type SP 88857105), spatel, sudip, sendok tanduk, kaca objek, ayakan mesh 80, kertas saring, corong, timbangan analitik (kenko), beaker glass (pyrex), oven (memmert UN 30), cawan persolen, labu erlenmeyer, $\mathrm{pH}$ universal, batang pengaduk, spatula, viskometer atago ${ }^{\circledR}$, sikat gigi, gigi palsu dan alat ukur warna gigi vitapan classical.

Bahan yang digunakan meliputi serbuk arang aktif tempurung kelapa, serbuk kopi, metilen blue (Merck), kalsium karbonat (Merck), sorbitol (Brataco Chemika), gliserol (Brataco Chemika), Natrium CMC (Merck), natrium lauryl sulfat (Merck), natrium benzoat (Merck), sacharin, menthol, akuades, $\mathrm{Na}_{2} \mathrm{CO}_{3} 5 \%, \mathrm{KCl}, \mathrm{NaCl}, \mathrm{CaCl}$, $\mathrm{NaH}_{2} \mathrm{PO}_{4.2} \mathrm{H}_{2} \mathrm{O}, \mathrm{Na}_{2} \mathrm{~S} .{ }_{9} \mathrm{H}_{2} \mathrm{O}$ dan Urea (Merck).

\subsection{Formulasi}

Formulasi pada sediaan pasta gigi yang digunakan telah dimodifikasi. Formula yang dimodifikasi adalah zat aktif yang diubah menjadi arang aktif tempurung kelapa (Cocos nucifera $L$ ) dengan variasi konsentrasi $0 \%, 6 \%, 10 \%$ dan $12 \%$ yang dibuat sebanyak masing-masing $200 \mathrm{~g}$. Formulasi Pasta Gigi dapat dilihat pada Tabel 1. 
Tabel 1. Formulasi Pasta Gigi

\begin{tabular}{lcccc}
\hline \multirow{2}{*}{ Komposisi } & \multicolumn{4}{c}{$\begin{array}{c}\text { Formula } \\
\text { (\%) }\end{array}$} \\
\cline { 2 - 5 } & F1 & F2 & F3 & F4 \\
\hline Arang aktif & 0 & 6 & 10 & 12 \\
tempurung & & & & \\
kelapa & & & & \\
CaCO 3 & 44 & 44 & 44 & 44 \\
Sorbitol & 18 & 18 & 18 & 18 \\
Gliserol & 10 & 10 & 10 & 10 \\
Na. CMC & 1 & 1 & 1 & 1 \\
Sacharin & 0,2 & 0,2 & 0,2 & 0,2 \\
Na. & 0,1 & 0,1 & 0,1 & 0,1 \\
Benzoat & & & & \\
Na. Lauryl & 1 & 1 & 1 & 1 \\
sulfat & & & & \\
Menthol & 0,3 & 0,3 & 0,3 & 0,3 \\
Akuades & Ad & Ad 200g & Ad & Ad 200 \\
& $200 \mathrm{~g}$ & & $200 \mathrm{~g}$ & $\mathrm{~g}$ \\
\hline Sumber: & & &
\end{tabular}

Sumber: Maesaroh dan Euis (2018) dengan modifikasi.

\subsection{Pembuatan Sediaan Pasta Gigi}

Natrium CMC dikembangkan di dalam air hangat sebanyak 1:20 kemudian didiamkan selama 15 menit lalu digerus hingga homogen (massa 1). Kalsium karbonat digerus, ditambahkan arang aktif tempurung kelapa digerus hingga homogen, lalu ditambahkan gliserol digerus hingga homogen, kemudian ditambahkan larutan sorbitol digerus hingga homogen dimasukkan ke dalam massa 1 digerus hingga homogen (massa 2). Saccharin, menthol dan Na.benzoat dilarutkan dengan sisa air, diaduk hingga homogen dimasukkan ke dalam massa 2 digerus dan diaduk hingga homogen. Na lauryl sulfat dimasukkan ke dalam massa 2, digerus homogen sampai terbentuk massa pasta, dimasukkan ke dalam wadah.

\subsection{Evaluasi Sifat Fisik Sediaan Pasta Gigi}

a. Uji organoleptik

Sediaan pasta gigi ditimbang sebanyak 1 gram lalu diamati meliputi konsistensi, warna dan bau. Replikasi sebanyak tiga kali pada masingmasing formula (Maesaroh dan Euis, 2018).

\section{b. Uji homogenitas}

Pasta gigi ditimbang sebanyak 1 gram lalu diletakkan pada kaca obyek untuk diamati homogenitasnya. Apabila tidak terdapat butiranbutiran kasar maka pasta gigi yang diuji dinyatakan homogen. Replikasi sebanyak tiga kali pada masing-masing formula (Syurgana et al., 2017).

\section{c. Uji pH}

Pasta gigi ditimbang sebanyak 1 gram kemudian dilarutkan dalam $25 \mathrm{ml}$ akuades. Celupkan kertas $\mathrm{pH}$ universal langsung pada sediaan yang sudah dilarutkan kemudian cocokkan dengan standar warna pada $\mathrm{pH}$ tertentu. Replikasi sebanyak tiga kali pada masing-masing formula (Maesaroh dan Euis, 2018).

\section{d. Uji viskositas}

Pengukuran viskositas menggunakan viscometer atago®. Pasta gigi ditimbang sebanyak 20 gram diletakkan pada plate viskometer dan dipasang. Spindel dipasangkan lalu spindle diturunkan hingga batas spindle tercelup ke dalam pasta gigi kemudian diaduk dengan kecepatan 2 rpm. Tunggu beberapa saat sampai nilai muncul pada alat viscometer lalu dicatat nilai tersebut. Replikasi sebanyak tiga kali pada masing-masing formula (Afni et al., 2015; Syurgana et al., 2017).

\subsection{Uji Aktivitas Pemutih Gigi}

Penelitian ini menggunakan 20 buah gigi palsu dibagi dalam 5 kelompok yaitu F1, F2, F3, F4 dan kontrol positif. Tahap awal yaitu gigi palsu diubah warnanya menjadi kekuningan dengan cara di rendam dalam larutan kopi selama 17 hari kemudian warna gigi diukur dengan shade guide vitapan classical (Togatorop et al., 2016). Serbuk kopi yang digunakan ditimbang sebanyak 30 gram ditambahkan air sebanyak $300 \mathrm{ml}$ aduk hingga merata (Yunita et al., 2016).

Masing-masing gigi palsu dimasukkan ke dalam pot salep yang telah berisi saliva buatan. Sampel gigi palsu dikeluarkan dari pot salep setiap kali melakukan perlakuan lalu dicuci dengan air kemudian gigi dikeringkan dengan handuk. Pengaplikasian dilakukan dengan cara menggosok gigi palsu dengan pasta gigi sebanyak 1 gram selama 3 menit, sampel dibersihkan pada air mengalir untuk membersihkan pasta gigi yang menempel pada gigi palsu. Masukkan kembali ke dalam pot salep. Prosedur ini diulang selama 14 hari, setelah 14 hari perubahan warna pada gigi masing-masing diukur dengan shade guide vitapan classical (Maesaroh \& Euis, 2018). 


\subsection{Analisis Data}

Analisis data pada penelitian ini dilakukan uji statistik menggunakan one-way anova pada uji $\mathrm{pH}$, uji viskositas dan uji aktivitas pemutih gigi. Uji ANOVA untuk mengetahui perbedaan dari setiap formula dengan menggunakan program SPSS 28.0.

\section{Hasil dan Pembahasan}

Tempurung kelapa (Cocus nucifera L) merupakan salah satu bahan yang dipilih sebagai bahan alami pada penelitian ini karena memiliki kandungan karbon aktif sebesar $74,3 \%$ serta memiliki kemampuan untuk menyerap kotoran dan sangat baik dalam membersihkan celah gigi yang sulit dibersihkan (Pertiwi et al., 2017). Arang aktif dapat memutihkan gigi dan membersihkan plak karena memiliki pori-pori jumlah besar yang akan membersihkan kotoran dengan adanya zat yang diserap (Lestari et al., 2020).

Sediaan pasta gigi arang aktif tempurung kelapa (Cocus nucifera $L$ ) dibuat sebanyak 4 formula di antaranya yaitu formula $1(0 \%)$, formula $2(6 \%)$, formula $3(10 \%)$ dan formula 4 (12\%). Evaluasi mutu sediaan pasta gigi arang aktif tempurung kelapa (Cocus nucifera L) meliputi uji organoleptik, uji homogenitas, uji $\mathrm{pH}$, uji viskositas dan uji aktivitas pemutih gigi selama 14 hari.

\subsection{Sifat Fisik Sediaan Pasta Gigi}

a. Organoleptik

Uji organoleptik dilakukan dengan mengamati warna, aroma serta konsistensi dari sediaan. Hasil pengamatan pada Tabel 2 didapatkan bahwa warna dan konsistensi sediaan pada masing-masing formula terdapat perbedaan sedangkan aroma tidak menunjukkan perbedaan. Hal ini dikarenakan terdapat perbedaan konsentrasi zat aktif arang aktif tempurung kelapa (Cocus nucifera $L$ ) pada masing-masing formula. Semakin tinggi konsentrasi arang aktif tempurung kelapa (Cocus nucifera $L$ ) yang digunakan maka warna dan konsistensi pasta gigi yang dihasilkan akan semakin hitam (pekat) dan semakin kental. Perbedaan konsentrasi pada zat aktif tidak mempengaruhi aroma pasta gigi tempurung kelapa (Cocus nucifera L) sehingga menunjukkan aroma yang sama yaitu berbau menthol (Afni et al., 2015).

Tabel 2. Hasil Organoleptik Sediaan Pasta Gigi

\begin{tabular}{cl}
\hline \multicolumn{1}{c}{ Formulasi } & \multicolumn{1}{c}{ Organoleptik } \\
\hline F1 (0\%) & Warna: cream \\
& Bau: menthol \\
& Konsistensi: berbentuk massa pasta \\
& kental sedikit cair \\
F2 $(6 \%)$ & Warna: hitam keabu-abuan \\
& Bau: menthol \\
& Konsistensi: berbentuk massa pasta \\
& kental dibanding F1 \\
& Warna: hitam \\
F3 $(10 \%)$ & Bau: menthol \\
& Konsistensi: berbentuk massa pasta \\
& kental dibanding F2 \\
& Warna: hitam pekat \\
F4 $(12 \%)$ & Bau: menthol \\
& Konsistensi: berbentuk massa pasta \\
& kental \\
\hline
\end{tabular}

b. Homogenitas

Uji homogenitas adalah salah satu tolak ukur kualitas sediaan pasta gigi karena bahan-bahan yang digunakan harus tercampur merata.

Tabel 3. Hasil Uji Homogenitas

\begin{tabular}{|c|c|}
\hline Formulasi & Homogenitas \\
\hline F1 $(0 \%)$ & Homogen \\
\hline $\mathrm{F} 2(6 \%)$ & Homogen \\
\hline F3 (10\%) & Homogen \\
\hline $\mathrm{F} 4(12 \%)$ & Homogen \\
\hline
\end{tabular}

Uji homogenitas menurut syarat mutu sediaan pasta gigi (SNI 12-3524-1995) yang menyebutkan bahwa sediaan pasta gigi harus homogen, tidak terlihat adanya gelembung udara, gumpalan dan partikel yang terpisah. Dari hasil uji homogenitas pada Tabel 3 menunjukkan bahwa telah memenuhi SNI yang ditandai dengan tidak terlihat adanya gelembung udara, gumpalan partikel yang terpisah dari sediaan pasta gigi. Bahan-bahan yang digunakan dalam pembuatan pasta gigi tercampur dengan sempurna dan bahan seperti pengikat serta humektan yang digunakan dalam sediaan pasta gigi mampu mencegah terjadinya pemisahan fase sehingga sediaan tetap terlihat homogen dan stabil (Warsy, 2016; Syurgana et al., 2017).

\section{c. Derajat keasaman $(\mathrm{pH})$}

Pengujian $\mathrm{pH}$ dilakukan untuk mengetahui tingkat keasaman atau kebasaan dari suatu sediaan (Rina, 2019). 
Tabel 4. Hasil Uji pH

\begin{tabular}{lccc}
\hline \multicolumn{1}{c}{ Formulasi } & Nilai $\mathbf{p H}$ & Standar & p-value \\
\hline F1 $(0 \%)$ & $6,67 \pm 0,57$ & pH pasta gigi= & 0,976 \\
F2 $(6 \%)$ & $6,67 \pm 0,57$ & $4,5-10,5$ (SNI & \\
F3 $(10 \%)$ & $6,63 \pm 0,57$ & $12-3524-1995)$ & \\
F4 $(12 \%)$ & $6,63 \pm 0,57$ & & \\
\hline
\end{tabular}

Keterangan: nilai $\mathrm{pH}$ tercantum adalah nilai mean \pm SD

Menurut SNI 12-3524-1995, syarat $\mathrm{pH}$ dari pasta gigi yaitu 4,5-10,5. Pada tabel 4, hasil pengukuran $\mathrm{pH}$ sediaan pasta gigi pada keempat formula yaitu direntang 6-7. Hal tersebut menunjukkan bahwa nilai $\mathrm{pH}$ yang terdapat pada pasta gigi telah memenuhi syarat. Nilai $\mathrm{pH}$ pasta gigi arang aktif tempurung kelapa (Cocus nucifera L) mengalami perbedaan pada masing-masing formula, tetapi hal ini masih masuk dalam standar persyaratan.

Perbedaan nilai $\mathrm{pH}$ pada masing-masing formula disebabkan karena faktor lingkungan seperti perubahan suhu karena penyimpanan dilakukan pada suhu ruang serta wadah penyimpanan yang kurang kedap sehingga memungkinkan udara dapat masuk (Lestari et al., 2020). Hasil uji statistik menggunakan one-way anova dengan memperoleh nilai $p$-value 0,976 $(>0,05)$ menunjukkan bahwa tidak terdapat perbedaan signifikan antara masing-masing kelompok.

\section{d. Viskositas}

Uji viskositas merupakan parameter utama kemudahan penggunaan sediaan dalam formulasi karena jika viskositas terlalu tinggi maka dapat mempersulit saat pengemasan dan pengeluaran sediaan pada tube begitu juga sebaliknya jika terlalu rendah akan mempersulit pengaplikasian ke gigi. Nilai standar viskositas sediaan semi solid yaitu 2.000-50.000 cps (Syurgana et al., 2017).

Hasil dari pengujian viskositas pada pasta gigi arang aktif tempurung kelapa (Cocus nucifera L) pada Tabel 5 sesuai dengan rentang yang ditetapkan. Nilai viskositas mengalami peningkatan pada masing-masing formula, tetapi masih memenuhi nilai standar viskositas sediaan semi solid. Semakin tinggi konsentrasi zat aktif yang digunakan dalam pasta gigi maka viskositas yang dihasilkan semakin tinggi. Hal ini disebabkan meningkatnya konsentrasi arang aktif tempurung kelapa (Cocus nucifera $L$ ) dalam pasta gigi, menyebabkan berkurangnya jumlah air dalam pasta gigi sehingga dalam mengembangkan $\mathrm{Na}$ CMC membutuhkan air yang lebih sedikit dan menghasilkan pasta gigi yang lebih kental (Afni et al., 2015).

Uji statistik menggunakan one-way anova dengan memperoleh nilai $p$-value $<0,01 \quad(<0,05)$ menunjukkan bahwa terdapat perbedaan signifikan antara masing-masing kelompok.

Tabel 5. Hasil Uji Viskositas

\begin{tabular}{lccc}
\hline Formulasi & $\begin{array}{c}\text { Nilai } \\
\text { viskositas } \\
(\mathbf{c p s})\end{array}$ & Standar & p-value \\
& $2479,46 \pm$ & Nilai standar & $<0,01$ \\
F1 $(0 \%)$ & 68,67 & semi solid & \\
F2 $(6 \%)$ & $6328,56 \pm$ & Viskositas $=$ & \\
& 227,00 & $2.000-50.000 \mathrm{cps}$ & \\
F3 (10\%) & $18059,67 \pm$ & (Syurgana et al., & \\
& 242,03 & 2017) & \\
F4 (12\%) & $29930,33 \pm$ & & \\
& 873,73 & & \\
\hline
\end{tabular}

Keterangan: nilai viskositas tercantum adalah nilai mean \pm SD

\subsection{Aktivitas Pemutih Gigi}

Pengujian aktivitas pemutih pasta gigi arang aktif tempurung kelapa (Cocus nucifera $L$ ) dilakukan untuk mengetahui daya bersih pada masing-masing formula. Gigi yang digunakan adalah gigi palsu berbahan resin akrilik. Bagian yang digunakan adalah rahang atas karena mempunyai permukaan yang cukup luas dibandingkan rahang bawah sehingga memudahkan kamera untuk mengambil obyek yang akan dinilai (Tunggal et al., 2015). Gigi direndam dengan larutan kopi selama 17 hari, hal ini dikarenakan agar basis gigi tiruan menjadi jenuh terhadap air (Togatorop et al., 2017).

Kopi dipilih sebagai bahan untuk memicu terjadi perubahan warna karena kopi mengandung senyawa tanin. Senyawa tanin yang ada di dalam kopi masuk melalui porositas pada basis gigi tiruan sehingga dapat menyebabkan perubahan warna kecokelatan pada suatu basis gigi tiruan. Penelitian yang dilakukan oleh Bazzi et al. (2014) menyatakan bahwa intensitas pewarnaan gigi tiruan akibat konsumsi kopi lebih tinggi dibandingkan teh, cola dan air. Potensi noda pada gigi juga lebih tinggi kopi jika dibandingkan dengan penggunaan tembakau.

Data yang sudah didapatkan sebelum dan sesudah pengaplikasian selanjutnya diurutkan skornya. 
Tabel 6. Hasil Uji Aktivitas Pemutih Gigi

\begin{tabular}{|c|c|c|c|c|}
\hline \multirow{2}{*}{ Formula } & \multirow{2}{*}{ Sampel } & \multicolumn{2}{|c|}{ Data Kualitatif } & \multirow[t]{2}{*}{$\begin{array}{l}\text { Nilai } \\
\text { Mean }\end{array}$} \\
\hline & & Sebelum & Sesudah & \\
\hline \multirow[t]{4}{*}{$\mathrm{F} 1(0 \%)$} & 1 & B3 & B3 & \\
\hline & 2 & B3 & B3 & 11,00 \\
\hline & 3 & B3 & B3 & \\
\hline & 4 & B3 & B3 & \\
\hline \multirow[t]{4}{*}{ F2 (6\%) } & 5 & B3 & $\mathrm{C} 2$ & \\
\hline & 6 & B3 & $\mathrm{C} 2$ & 6,75 \\
\hline & 7 & B3 & $\mathrm{C} 1$ & \\
\hline & 8 & B3 & $\mathrm{C} 2$ & \\
\hline \multirow[t]{4}{*}{ F3 $(10 \%)$} & 9 & B3 & $\mathrm{C} 1$ & \\
\hline & 10 & B3 & $\mathrm{C} 1$ & 5,25 \\
\hline & 11 & B3 & $\mathrm{A} 2$ & \\
\hline & 12 & B3 & D2 & \\
\hline \multirow[t]{4}{*}{ F4 $(12 \%)$} & 13 & B3 & D2 & \\
\hline & 14 & B3 & $\mathrm{B} 2$ & 2,75 \\
\hline & 15 & B3 & B1 & \\
\hline & 16 & B3 & B2 & \\
\hline \multirow{4}{*}{$\begin{array}{l}\text { Kontrol } \\
\text { positif }\end{array}$} & 17 & B3 & B1 & \\
\hline & 18 & B3 & B1 & 1,50 \\
\hline & 19 & B3 & B1 & \\
\hline & 20 & B3 & B2 & \\
\hline
\end{tabular}

Keterangan:

Kontrol positif: pasta gigi pembanding merk Zact A2 = Merah-coklat level 2

B1 = Merah-kuning level 1

B2 = Merah-kuning level 2

B3 = Merah-kuning level 3

$\mathrm{C} 1=$ Abu-abu level 1

$\mathrm{C} 2$ = Abu-abu level 2

D2 = Merah-abu-abu level 2

Urutan skor perubahan warna pada alat shade guide vitapan classical adalah sebagai berikut: $\mathrm{B} 1=1, \mathrm{~A} 1=2, \mathrm{~B} 2=3, \mathrm{D} 2=4, \mathrm{~A} 2=5, \mathrm{C} 1=6, \mathrm{C} 2=7$, $\mathrm{D} 4=8, \mathrm{~A} 3=9, \mathrm{D} 3=10, \mathrm{~B} 3=11, \mathrm{~A} 3,5=12, \mathrm{~B} 4=13$, $\mathrm{C} 3=14, \mathrm{~A} 4=15, \mathrm{C} 4=16$ (Liena et al., 2011). Jadi semakin tinggi nilai yang dihasilkan pada shade guide maka semakin gelap warna gigi tersebut atau sebaliknya (Ghalib \& Ayuandyka, 2017).

Hasil pengamatan diperoleh data secara kualitatif, sediaan pasta gigi selama 2 minggu pengaplikasian didapatkan bahwa bahan alami arang aktif tempurung kelapa (Cocus nucifera $L$ ) mampu memberikan perubahan warna atau mencerahkan kembali gigi yang telah mengalami diskolorasi yang disebabkan oleh kopi. Uji statistik menggunakan one-way anova diperoleh nilai $p$-value yaitu $0,037 \quad(<0,05)$ yang berarti terdapat perbedaan signifikan pada perubahan warna gigi antara masing-masing formula dan pasta gigi pembanding zact.
Uji berikutnya adalah uji deskriptif. Uji ini dapat dilihat dari nilai mean yang diperoleh. Nilai mean merupakan nilai rata-rata skor yang didapat dari masing-masing formula. Semakin kecil nilai mean maka semakin signifikan aktivitas pasta gigi sebagai pemutih gigi.

Kontrol positif pada penelitian ini menggunakan pasta gigi zact sebagai pasta gigi pembanding karena pasta gigi ini diformulakan secara khusus bagi pengguna kopi dan teh. Pasta gigi zact menunjukkan nilai mean terendah yaitu 1,5 yang berarti bahwa pasta gigi ini yang paling efektif untuk memberi perubahan pada warna gigi dibandingkan dengan F1, F2, F3 dan F4. Nilai berikutnya diikuti oleh F4 (12\%), F3 (10\%) dan F2 $(6 \%)$ yang dianggap memiliki aktivitas yang signifikan sebagai bahan alami pemutih gigi.

\section{Kesimpulan}

Sediaan pasta gigi arang aktif tempurung kelapa (Cocos nucifera L) pada F1, F2, F3 dan F4 memiliki sifat fisik yang baik setelah dievaluasi mutu fisiknya meliputi uji organoleptik, uji homogenitas, uji $\mathrm{pH}$ dan uji viskositas serta mampu memberikan perubahan warna pada gigi. Uji statistik pada sediaan pasta gigi arang aktif tempurung kelapa menunjukkan bahwa memiliki perbedaan aktivitas yang signifikan sebagai bahan alami pemutih gigi.

\section{Daftar Pustaka}

Afni, N., Said, N., \& Yuliet., (2015). Uji Aktivitas Antibakteri Pasta Gigi Ekstrak Biji Pinang (Areca catechu L.) Terhadap Streptococcus mutans dan Staphylococcus aureus. Galenika journal of pharmacy, 1(1), 48-58.

Asmawati, \& Aulia, M. (2016). Pemanfaatan Buah Strawberry sebagai Bahan Pemutih Gigi. Makassar Dent J, 5(2), 40-43.

Bazzi, J. Z., Bindo, M. J. F., Rached, R. N., Mazur, R. F., Souza, S. V. and, \& De, E. M. (2014). The Effect Of At-Home Bleaching And Toothbrushing On Removal Of Coffee And Cigarette Smoke Stains And Color Stability Of Enamel. The Journal of The American Dental Association, 143(5), 1-7. https://doi.org/10.1136/bmj.c4875.7. 
Ghalib, N., \& Ayuandyka, U. (2017). Prevalensi Diskolorisasi Gigi Pada Anak Prasekolah Di Kota Makassar Prevalence Of Tooth Discoloration In Preschool Children In Makassar. Makassar Dental Jurnal, 6(2), 6672.

Lestari, U., Syamsurizal, \& Septima, N. R. (2020). Uji Aktivitas Pasta Gigi Arang Aktif Cangkang Sawit (Elaeis guineensis) Antiplak Pada Perokok Secara Invitro Uce. SCIENTIA Jurnal Farmasi dan Kesehatan, 10(2), 177186.

Liena, C., Lozano, E., Amengual, J., \& Forner, L. (2011). Reliability Of Two Color Selection Devices In Matching And Measuring Tooth Color. Journal of Contemporary Dental Practice, 12(1), 19-23.

Maesaroh, I., \& Euis, N. (2018). Uji Efektivitas Penggunaan Pasta Gigi Ekstrak Kulit Pisang Kepok (Musaparadisiaca. L) Sebagai Pemutih Gigi. CERATA Jurnal Ilmu Farmasi, 9, 3948.

Pambayun, G. S., Yulianto, R. Y. E., Rachimoellah, M., \& Putri, E. M. M. (2013). Pembuatan Karbon Aktif Dari Arang Tempurung Kelapa Dengan Aktivator Zncl2 Dan $\mathrm{Na}_{2} \mathrm{CO}_{3}$ Sebagai Adsorben Untuk Mengurangi Kadar Fenol Dalam Air Limbah. Jurnal Teknik Pomits, 2(1), 116-120.

Pertiwi, U. I., Eriwati, Y. K., \& Irawan, B. (2017). Surface Changes Of Enamel After Brushing With Charcoal Toothpaste. Journal of Physics: Conference Series, 884(1), 1-9.

Rahardjo, A., Gracia, E., Riska, G., Adiatman, M., \& Maharani, D. A. (2015). Potential Side Effects of Whitening Toothpaste on Enamel Roughness and Micro Hardness. International Journal of Clinical Preventive Dentistry, 11(4), 239-242.

Riani, M. D., Oenzil, F., \& Kasuma, N. (2015). Pengaruh Aplikasi Bahan Pemutih Gigi Karbamid Peroksida 10\% dan Hidrogen Peroksida 6\% secara Home Bleaching terhadap Kekerasan Permukaan Email Gigi. Jurnal Kesehatan Andalas, 4(2), 346-352.

Rina Asrina. (2019). Formulasi Stabil Pasta Gigi dari Ekstrak Etanol Daun Gamal (Gliricida sepium) sebagai Pencegah Karies Gigi ). Jurnal Farmasi Sandi Karsa, 5(2), 99-104.

Saputro, E. A., Wulan, V. D. R., Winata, B. Y., Yogaswara, R. R., \& Erliyanti, N. K. (2020). Process of Activated Carbon form Coconut Shells Through Chemical Activation. Natural Science: Journal of Science and Technology, 9(1), 23-28.

Syurgana, M. U., Febrina, L., \& Ramadhan, A. M. (2017). Formulasi Pasta Gigi dari Limbah Cangkang Telur Bebek. Proceeding of the 6th Mulawarman Pharmaceuticals Conferences, 7-8.

Togatorop, R. S., Rumampuk, J. F., \& Wowor, V. N. S. (2017). Pengaruh Perendaman Plat Resin Akrilik Dalam Larutan Kopi Dengan Berbagai Kekentalan Terhadap Perubahan Volume Larutan Kopi. e-GIGI, 5(1), 19-23.

Torres, C. R. G., Perote, L. C. C. C., Gutierrez, N. C., Pucci, C. R., \& Borges, A. B. (2013). Efficacy Of Mouth Rinses And Toothpaste On Tooth Whitening. Operative Dentistry, $38(1), 57-62$.

Tunggal, E. G., Dharmautama, M., \& Jubhari, E. H. (2015). Perubahan Warna Basis Akrilik Setelah Penggunaan Pasta Pembersih Gigitiruan Rosella (The Changes Of Acrylic Base Color After Using Roselle Pasta Denture Cleanser). Journal of Dentomaxillofacial Science, 14(1), 25-28.

Warsy, W., Chadijah, S., \& Rustiah, W. (2016). Optimalisasi Kalsium Karbonat dari Cangkang Telur untuk Produksi Pasta Komposit. Skripsi. 4(2).

Yuniarti, Achaditani, N. M. (2016). Penggunaan Pemutih Gigi Mengandung Hidrogen Peroksida $40 \%$ Dibanding dengan Strawberry (Fragaria $\mathrm{X}$ ananassa) terhadap Teeth Bleaching Hydrogen Peroxide $40 \%$ Compared with Strawberry (Fragaria X ananassa) to Enamel Thickness , Calcium Level and Compres. Global Medical and Health Communication, 4(1), 7-15.

Yuningsih, L. M., Mulyadi, D., \& Kurnia, A. J. (2016). Pengaruh Aktivasi Arang Aktif dari Tongkol Jagung dan Tempurung Kelapa 
Terhadap Luas Permukaan dan Daya Jerap Iodin. Jurnal Kimia VALENSI, 2(1), 30-34.

Yunita, T. G., Haryani, W., \& Sutrisno. (2016). Efektivitas Antara Buah Stroberi Dengan Buah Jeruk Lemon Sebagai Bahan Alami Pemutih Gigi (Secara In Vitro). Jurnal of oral health care, 3(1), 1-11. 